\title{
Refleksi dan Evaluasi Stigma 5 Festival Monolog Nasional di Universitas Negeri Malang
}

\author{
Roci Marciano \\ Sekolah Tinggi Kesenian Wilwatikta Surabaya \\ rocimarci@gmail.com
}

\begin{abstract}
Abstrak
Monolog dalam seni teater dan drama penting untuk di pelajari saat ini, karena memberikan dampak positif bagi seorang aktor, baik itu di atas panggung, maupun pada kehidupan itu sendiri. Kecerdasan yang bisa dipelajari dalam belajar monolog tentu saja bukan hanya berani tampil sendirian di atas panggung dengan menyampaikan kisah. tetapi nilai yang paling berharga adalah ketika seorang manusia mampu menghapalkan hasil pemikiran seorang penulis naskah, merespon segala tatanan artistik dengan kecerdasan lahiriah dan batiniah sebagai perangkat keaktoran untuk disampaikan kepada penonton. Refleksi dan evaluasi perlombaan, perlu disampaikan demi kemajuan para pelaku monolog.
\end{abstract}

Kata Kunci: monolog; aktor; teater; drama; refleksi

\begin{abstract}
Monologue in theater and drama is important to studied in this time, because it give positive impact for an actor, for stage and the life it self. Intelligence that can be studied in learning about monologue of course bot merely dare to come up alone with submit story. But value most valuable when a human can to memorized thinking result a draft author, responsive all artistic order with intelligence borns and mind as impersonation ware to submitted to onlooker. Reflection and race evaluation is needen to submitted by progress of monologue actor.
\end{abstract}

Keywords: monologue; actor; theater; drama; reflection

\section{PENDAHULUAN}

Soluloqueadalah istilah yang berasal dari bahasa Yunani, yaitu penggambaran seorang tokoh yang menceritakan isi hatinya agar di dengar oleh penonton, soluloque inilah yang kemudian menjadi akar atau ibu yang melahirkan istilah Monodrama dalam teater atau lebih sering dikenal dengan istilah monolog. Soluloque biasanya digunakan oleh tokoh-tokoh teater yang menulis naskah yang dianggap sebagai naskah-naskah besar sepanjang zaman seperti naskah Sophochles, 
Euripides, Aristhopanes, Aeschylus, William Shakespeare, Gothe, Jean Paul Sartre, Albert Camus, W.S. Rendra, Arifin C Noer, Putu Wijaya, Nano Riantiarno dan masih banyak penulis besar lainnya lagi.

Rata-rata di naskah yang penggambaran watak serta karater tokohnya yang kuat, soluloque ini menjadi ciri dari naskah lakon tersebut, dan saat soluloque ini pulalah penonton bisa melihat kualitas seorang aktor dalam menghidupkan watak tokohnya.Mengutip apa yang di tulis oleh seniman teater Indonesia Nano Riantiarno di dalam pengantar buku Sphinx Triple X yang mengatakan:

Tradisi 'monodrama' Yunani klasik itu, kemudian dilanjutkan oleh Wiliam Shakespeare dalam banyak karya dramanya. Tapi Shakespeare menyebutnya sebagai solilog. Atau soliloque. Itulah adegan ketika seorang pelakon mengungkapkan fikiran dan perasaannya, sendirian, tanpa kehadiran pelakon lain. Sebagaimana mono drama dalam karya Aeschylus, soliloque juga masih merupakan bagian dari sebuah drama panjang (Riantiarno, xiv: 2004).

Dalam naskah klasik barat soliloque ini panjang-panjang, bahkan disebutnya sudah bukan soliloque lagi, melainkan sudah taraf monolog, monodrama, melodrama, one man play, one man show, teater solo dll. Tentu saja tidak cukup energi Penulis untuk mengulas satu persatu yang menggambarkan pertunjukan teater yang diperankan oleh seorang aktor tersebut. Pada intinya monolog adalah berbicara sendiri dan lawannya ialah dialog.Monolog juga suara hati yang diucapkan, dan seyogyanya bisa didengar oleh penonton dari bangku yang paling depan sampai bangku yang paling belakang. Pada kesempatan ini Penulis akan fokus membahas monolog saja, jika menyinggung pembahasan mono play dan one man show, tentu saja tidak akan tuntas, setidaknya Penulis menyentuh dasarnya.

Sebagai suatu genre dalam kesenian teater saat ini, monolog tentu saja sudah mengalami perkembangan yang signifikan, baik dari sajian dalam bentuk pertunjukan, maupun dari segi aliran sebagai keilmuan. Sehingga wajar jika perkembangan monolog tersebut mengalami banyak bentuk, seperti teater yang juga terbagi dalam teater realis yang memuat teater realisme konvensional, realis epik dan realis sugestif. Begitu juga dengan teater non realis yang memuat kotemporer, eksperimental, tradisional, absurd, dadais, surealis, postrealis dll.

Jika dalam ranah monolog maka tidak menutup kemungkinan ada yang namanya one man play, soluloque drama, teater solo, one man show dll. Tapi dalam kesempatan yang singkat ini lagi-lagi Penulis hanya fokus pada monolog karena memang festival stigma lima ini fokusnya pada monolog. Bila diartikan dari bahasa Inggris monologue artinya bicara sendiri, dan kata monolog ini sendiri telah diserap dalam bahasa Indonesia yang juga diartikan sebagai pembicaraan yang dilakukan dengan diri sendiri atau sorang pelaku tunggal dalam sandiwara yang membawakan percakapan seorang diri. Mengutip catatan Alterman dalam Creating your own monologuemengatakan; A long monologue or monodrama is a one-person play. Monodramas can be a powerful form of theater (Alterman, 2005: 4). 
Penulis juga sepakat bahwa monolog sesungguhnya adalah kata hati yang diformulsikan dalam bentuk cakapan, dan kata hati ini dalam drama dibagi tiga macam diantaranya ada monolog, soluloque dan aside (Abdullah, 2000: 86). Soluloque telah dijelaskan di atas, sementara aside adalah lontaran fikiran berupa komentar atau kritikan terhadap adegan yang sedang berlangsung. Misalnya si aktor mengomentari kejadian di balik sadewing sehingga penonton tahu bahwa di luar area permainan aktor masih ada kehidupan lain yang sedang berlangsung. Monolog adalah cerita yang berupa perenungan terhadap peristiwa yang telah terjadi, kata kuncinya adalah diperankan oleh seorang aktor di atas panggung. Hal ini seharusnya menjadi pegangan jika semua bersepakat, karena menurut Lanvord Wilson dalam Shengold catatan bukunya The Actor's Book Of Contemporary Stage Monologues mengatakan bahwa monolog It's almost a oneact play,(Shengold, 1987: 324).Begitu juga menurutTina Howe dalam shengold mengatakan;A monologue has to do with revealing things that the character has been unable to reveal before. So it's a very precious moment (Shengold, 1987: 331).

Monolog dalam pementasan teater bisa disebut sebagai, seorang aktor yang bercerita atau berperan secara langsung kepada penonton, dan mengekspresikan perasaan batin tokoh yang terdapat di dalam naskah sebagai wujud demonstrasi akting secara psikologi, fisiologi dan sosiologi tokoh. Kata kunci satu aktor dan satu tokoh yang bercerita adalah esensi dari monolog. Menyapa penonton bahkan juga masih bisa diberlakukan dalam monolog, yang menjadi alasan mengapa
Penulis berani mengatakan hal ini, ditandai oleh seorang pewarta dalam naskah Oidipus yang di tulis oleh Sopochles. Bercerita kepada masyarakat atas peristiwa tragedi besar yang melanda kerajaan Thebes. Sang aktor mampu memperlihatkan kembali kejadian yang ia lihat untuk dilihat bersama-sama oleh penonton.

Berbeda dengan mono play, tentu saja masih kembangan dari monolog, sebab sang aktor bercerita tapi tidak lagi mengaktifkan penonton dengan kata saudara-saudara sebagai ruang kesadaran, melainkan dengan pentas seorang diri, sang aktor mewujudkan tokoh selain tokoh utama yang ia mainkan. Misal tokoh A adalah dasarnya, tapi untuk menceritakan tokoh B, C dan D maka sang aktor berubah menjadi tokoh tersebut, tentu saja perubahan ini total dengan segala perangkat dari masing-masing tokoh yang akan diwujudkan. One man show adalah istilah yang menampung pementasan yang bisa mewadahi apa yang terjadi di dalam monolog seperti bercerita, juga teknik yang ada pada mono play sebagai bentuk pengayaan dan penguasaan teknik yang dimiliki oleh seorang aktor, secara tidak langsung dalam one man show aktor harus menguasai akting, dancing and singing. Karena one man show, perkawinan monolog dan mono play, dan one man show menjadi kekuatan seorang aktor untuk melakukan teater solo.

Bila menganalisis dan mengamati hasil dari pementasan peserta festival monolog Nasional stigma lima UM. Maka tampak bahawa para aktor telah melakukan suatu aksi yang disebut dengan mono play. Sebab yang tampak, dari semua aktor yang ikut lomba, rata-rata memainkan lebih dari satu tokoh, meskipun tokoh yang diwujudkan belum 
menyentuh pada wilayah karakter dan watak, melainkan, aktor yang berlomba baru sampai pada wilayah teknis, tubuh plastis dan ekshibisionis. Itulah mengapa refleksi dan evaluasi ini menjadi penting untuk membaca hasil dari festival monolog Nasional stigma 5 Universitan Negeri Malang.

Adapun landasan teori yang penulis gunakan untuk menganalisis gaya akting Supali yakni, menggunakan teori aktingnya Eka D Sitorus dalam bukunya The Art Of Acting, Seni Peran Untuk Teater, Film dan TV. Teori Akting Eka D Sitorus juga membedakan antara akting representasi dan akting presentasi. Melalui pendekatan teori Eka D Sitorus ini penulis akan menyingkap apakah akting dalam pementasan monolog ini termasuk pada kategori akting representasi (formalisme) atau presentasi (realisme).

Teori Akting John Harrop dan Sabin. R. Epstein, dalam buku Gaya Akting (Akting With Style) penulis gunakan untuk menemukan dan menentukan gaya berakting aktor monolog di stigma lima UM. Teori akting John Harrop dan Sabin. R. Epsteinmemberikan petunjuk dalam menganalisis gaya akting dalam pementasan seorang aktor. Teori ini digunakan untuk memperkuat pernyataan yang penulis temukan terhadap hasil analisis. Teori akting John Harop dirasa mampu membantu untuk mengkaji objek yang penulis teliti mengingat bahwa akting tidak terlepas dariberbagai teknik dan gaya dalam pementasannya.

Gaya berarti mengetahui jenis lakon drama yang tengah diperankan. Seorang aktor haruslah berbuat tidak lain selain menciptakan suatu lakon yang konsisten dengan emosinya sendiri dan rasa identitas pribadinya sendiri (Harrop\&Epstein).

\section{METODE}

Metode yang dipakai untuk meneliti hasil lomba ini ialah, menggunakan metode penelitian kualitatif ST Hanggar Budi Prasetya (2013). Metode ini untuk menentukan tahapan operasional tentang kebenaran-kebenaran suatu penelitian. Penulis meyakini adanya kejelasan tentang metode kualitatif yang diuraikan oleh ST Hanggar dan merasa bahwa teori inilah yang paling sesuai dengan objek yang penulis teliti. Melihat sosok para aktor secara eksploratif dan prediktif, maka metode yang diurai ST Hanggar bisa diterapkan di lapangan. Seperti ungkapannya;Penelitian kualitatif cocok digunakan untuk mengungkap sifat pengalaman seseorang dan memahami sesuatu dibalik fenomena yang sedikitpun belum diketahui. Metode ini dapat memberi rincian yang kompleks tentang fenomena yang sulit diungkap oleh metode kuantitatif (Hanggar, 2013:14).

Konsep penelitian diharap mampu memberi cara dan jalan termudah untuk mengungkap sisi negatif dan positif penelitian, terutama dalam penyikapan gaya aktingSupali yang dipertanyakan kebenaran penelitiannya. Analisis yang juga digunakan dalam penelitian ini ialah analisis dialektik, yakni mengamati suatu objek dan kemudian melakukan analisis berdasarkan apa yang tampak, juga didengar dan dirasakan, melalui analisis dialektik ini bisa ditemukan hal-hal yang bersifat sesuai dengan logika berfikir. Untuk mendapatkan fakta logis berdasarkan analisis dialektik tersebut, kerja penelitian yang dilakukan ialah dengan mewujudkan penelusuran pementasan secara struktur dan tekstur. Analisis struktur dan tekstur inilah yang kemudian akan 
menjadi kunci untuk merefleksi dan mengevaluasi.

\section{HASIL DAN PEMBAHASAN}

Penulis mengucapkan salut, ternyata begitu banyak yang berminat untuk mengikuti event ini, sebab awalnya telah dilakukan kurasi dari 28 dokumentasi dari 28 Provinsi, diambil 16 besar untuk berlomba dan yang ikut lomba 15 grup (satu grup tidak ada konfirmasi). Berdasarkan dari pernyataan panitia, sebenarnya banyak yang sudah mendaftar, namun berdasarkan dari penilaian panitia, yang lolos untuk masuk dalam kategori kurasi hanya dua puluh delapan video, kecuali wilayah Papua yang belum turut serta.

Dalam perlombaan pementasan teater yang paling riskan ialah teknis itu sendiri. Teknis mau tidak mau menjadi hal penting untuk diperhitungkan, karena teknis inilah yang kemudian menemani dan membantu aktor dalam menyampaikan pesan-pesannya pada saat pementasan. Baru setelah penguasaan teknis berhasil, disempurnakan dengan perasaan. Sehingga jika teknis dan perasaan ini bisa kawin dalam pementasan, maka bisa dipastikan pertunjukan akan menjadi utuh, meskipun hanya dimainkan oleh seorang aktor di atas panggung (monolog).

Mengapa Penulis mengatakan pentingnya penyikapan teknis, karena secara keseluruhan Penulis melihat bahwa tim yang terlibat dalam pementasan di Stigma lima ini masih belum detil menyikapi panggungnya, bahkan masih ada yang ala kadarnya. Misalnya dari wilayah tatanan artistik secara keseluruhan masih banyak peserta yang belum singkron menggarap kesinambungan antara tata busana, tata panggung, tata cahaya, tata rias dan tata musik. Tatanan yang terlihat dalam mendukung karakter dan permainan aktor ini tentu saja perlu diperhatikan.

Jika konsepnya ingin menabrak tatanan teknis, seharusnya juga diperhitungkan agar semua yang terlihat, terdengar dan terasa adalah bagian dari konsep yang disengaja, tapi yang tampak dalam realitasnya, bahwa misteknis tatanan artistik secara keseluruhan terjadi, memang belum tergarap sebagaimana mestinya, jikapun tergarap belum dengan perhitungan yang matang. Refleksi dan Evaluasi dalam festival monolog stigma lima ini sengaja penulis pilih salah satu dari lima belas pementasan karya untuk diulas, karena dari satu pementasan ini mewakili secara keseluruhan.

\section{Refleksi}

Komunitas Batra dari Riau mementaskan Naskah "Wanci": sebagai gimik awal, tata suara yang menghadirkan suara kereta lewat dengan lampu tiba-tiba merah dan blackout memang terasa janggal, sebab yang terasa bahwa adegan awal ini hanya gimik, memang tidak masalah jika akhirnya menjadi tempelan. Sebab adegan selanjutnya terdengar suara musik dangdut yang cukup memikat, karena musik ini dekat dengan rakyat Indonesia, tapi sayang sang aktor tampak belum begitu faseh dalam menghidupkan suasana musik dangdut sebagai gebrakan awal pementasan ini. Antara akting dan bukan akting masih tipis untuk dibedakan Mungkinada yang beranggapan persoalan ini tidak penting, tetapi sebenarnya justru kasus-kasus perbatasanantara akting dan bukan-akting ini yang akan memperdalam 
pemahaman tentang teori akting dan hakekat seni akting (Kirby, 1998: 80).

Alasannya tentu saja jelas, sebab aktor terbebani oleh evaluasi dua juri yang gaya aktingnya mirip dengan aktor yang pertama kali memerankan naskah ini. Pendukung akting seperti tata panggung juga terlalu baru, bahkan sejarah ruang dan waktu belum terbaca, bila ingin membuat seting dengan suasana baru selesai dicat, harusnya yang tampak tidak seperti baru saja selelsai dicat untuk kebutuhan pentas, sebab sentuhansentuhan kecil yang membuat tempat itu kotor dibutuhkan, agar menambah daya dramatik, sayang hal itu belum terlihat. Secara visual kostum memang sudah mewakili sebagai orang yang lama hidup di jalan, orang stres, tapi sendal yang dikenakan tampak terlalu bersih, jelas sekali sendal jepit itu juga kehilangan sejarahnya, rias sudah bagus, hanya saja ekspresi terlalu sering ditutupi oleh rambut, hingga penonton kesusahan untuk melihat mata sebagai jendela hati seorang aktor. Penyutradaraan tampak baru fokus pada penguasaan teknik bermain, belum detil, mengolah rasa, irama dialog dan tangga dramatik. Keharmonisan budaya salah satunya diwakili oleh musik dangdut, itupun akhirnya menjadi tempelan saja.

Aktor secara modal bermain di atas panggung sebenarnya sudah cukup, hanya saja secara olahan rasa dan irama belum terwadahi dengan baik, dibeberapa momen banyak yang monoton. Terutama saat berganti-ganti peran menegaskan aktor dalam aktingnya tampak belum memiliki system untuk mencipta secara organik (Sitorus, 2002: 32). Sebab berhasilnya aktor menciptakan peran secara organik bertujuan untuk menciptakan cerminan bagi penonton yakni, secara tidak langsung aktor menciptakan ilusi. Ilusi permainan ini yang belum terasa secara maksimal, karena yang baru tampak pada permukaan saja.

Meskipun ada niatan untuk mewujudkan akting kearah presentatif, namun yang tampak dari pementasan tokoh Wanci ini akhirnya representatif, sebab adanya tendensi berubah-rubah menciptakan tokoh lain dari permainan, akhirnya tidak konsistennya aktor dengan tokoh utama yang ia mainkan membuat aktingnya menjadi representatif. Akting representasi pada dasarnya berusaha untuk mengimitasikan dan mengilustrasikan tingkah laku karakter. Aktor representasi percaya bahwa bentuk karakter diciptakan untuk dilihat dan dieksekusi di atas panggung. Dengan kata lain, akting representasi berusaha memindahkan "pyche" (jiwanya) sendiri untuk mengilustrasikan tingkah laku karakter yang dimainkan sehingga penonton teralienasi dari si aktor. Tendensi akting representasi adalah formal dan cendrung mengikuti "fashion" yang ada. Tetapi empati dengan tingkah laku manusia, keikut sertaan emosi antara aktor dan penonton tidak ada (Sitorus, 2002: 19).

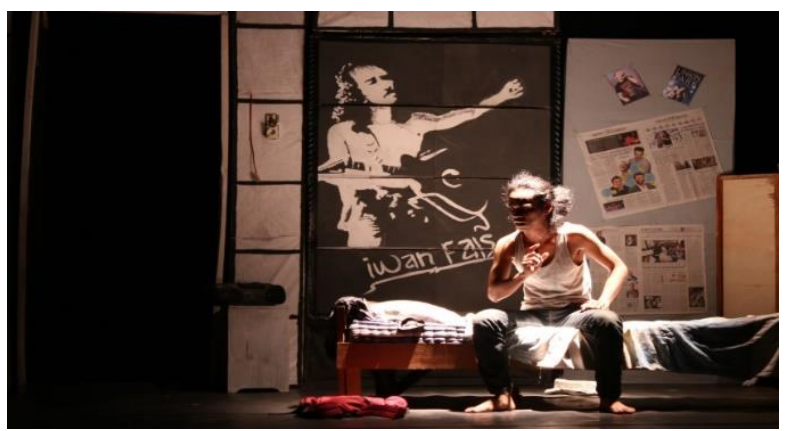

Gambar 1. Foto salah satu peserta Monolog Nasional Stigma 5, UM. (Dokumentasi oleh: Roci Marciano, 2018) 


\section{Evaluasi}

Walau bagaimanapun karena ini monolog, hendaknya para aktor yang berperan harus tampak muncul akting dan seni aktingnya, perasaan tokohnya diharapkan ditampilkan dengan penuh penjiwaan, tapi masih banyak yang mentah, bahkan ada yang kebingungan, juga tidak menutup kemungkinan blibet dalam wicara. Secara tidak langsung apa yang tampak justru menjadi penanda bahwa adanya kurang latihan atau kurang eksplorasi, Penulis berharap ini menjadi pertimbangan bersama.

Contoh akting menjadi yang diharapkan oleh Stanislavsky, yaitu bertujuan untuk membenarkan laku, pembenaran tidak hanya berlaku bagi motivasi tetapi juga bagi usaha untuk mempertahankan laku. Mencari inspirasi, bagi aktor gaya Stanislavsky dengan diam-diam menunjukkan kebenaran laku yang ada. Garis laku menghilangkan bangunan sosial dan dengan demikian mengubah alam realita secara politis. Membenamkan penonton kedalam suatu arus tujuan yang berubah beserta konsekuensinya yang muncul, perubahan tersebut akan mengembangkan ilusi bahwa gambaran sekuens penyebabnya dalam beberapa hal bersifat absolut. Sekuens dimana a menyebabkan b menyebabkan c secara berlebihan menyatakan bahwa, menghadirkan a (kondisi yang ada), c pasti terjadi (Mitter, 1999: 94).

Juga Penulis mengkritisi para aktor yang masih belum stabil pengolahan vokalnya, tubuh juga masih banyak yang kaku, bahkan saat tidak berbicara, sehingga yang tampak adalah tidak selaras dan seimbang antara suara dan tubuh. Padahal monolognya tentang tragedi misalnya, tapi tubuhnya masih komedi, pada intinya masih banyak tubuh aktor yang belum berbicara. Untuk penjiwaan lagi-lagi Penulis belum menemukan. Hal ini apakah karena faktor kelelahan atau persoalan tekanan sutradara, atau justru sang aktor merasa ada beban moral, Penulisjuga kurang tahu. Karena memang pada esensinya teater itu adalah tontonan langsung. Pentingnya penjiwaan dalam bermain monolog itu sangat membantu menculnya inner aktor. Berikut ini juga beberapa trik yang bisa membantu para aktor untuk mewujudkan monolog yang baik, Seperti yang dikatakan Roznowzki dalam bukunya Inner Monologue In Acting(2013) mengatakan:

Inner monologue; interior monologue; conscience; good angel vs.bad angel; voices in your head; stream of consciousness, free association, underthoughts; a conversation with oneself; subvocalization;cognitive linguistics; language of thought; libido: no matter what thetheoretical or olloquial label, the result is the same-a constant,nearly uninterrupted flow of thoughts that occur in every person 'smind. For actors, the trick isunderstanding, harnessing, and adaptingtheir personal inner thoughts in order to create the IM for the characterthey portray. For the director, learning to speak this most intimateinterior language with the actors paves the way for more depth indiscussing performance and a compelling connection to the cast. Foreducators, the goal is to assist a student in understanding the nuancesof the individual personal IM and character IM ( Roznowzki, 2013: 2)

Aktor adalah kata kunci dalam pementasan monolog, tantangannya sangat besar, sebab dengan sendirian harus menghidupkan banyak hal, itulah sebabnya mereka yang berani bermain monolog adalah manusia-manusia spesial, apalagi monolog 
yang dipentaskan bisa memberikan pembelajaran serta tuntunan yang baik pada penontonnya, tentu inilah yang diharapkan. Tuntunan tersebut bisa tersimpan di dalam diri penonton berkat adanya pukauan akting para aktor yang membekas, seperti saat kita membicarakan film yang kita sukai, teater yang kita sukai dan para aktor yang kita sukai. Dalam memerankan tokoh, seharusnya yang menjadi target ialah orang-orang membicarakan pentas dan tokoh yang dimainkan. Tapi dalam pementasan yang Penulis tonton kali ini, memang tampaknya belum terlihat, mungkin dan semoga ini semua karena Penulis yang menontonnya, harapannya semoga seiring proses nantinya akan berbeda, sebab pada kenyataannya aktor yang bermain dalam monolog stigma lima UM ini secara keseluruhan masih menggunakan akting representasi.

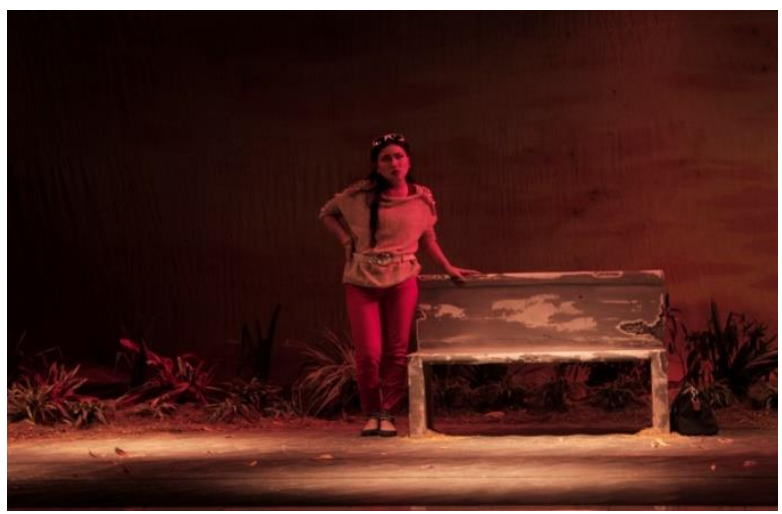

Gambar 2. Foto salah satu peserta Monolog Nasional Stigma 5, UM. (Dokumentasi oleh: Roci Marciano, 2018)

Akting representasi berusaha memindahkan "psyche" (jiwanya) sendiri untuk mengilustrasikan tingkah laku karakter yang dimainkan sehingga penonton teralienasi dari si aktor. Akting presentasi adalah akting yang berusaha menyuguhkan tingkah laku manusia melalui diri si aktor, melalui pengertian terhadap dirinya sendiri dengan hasil mengerti karakter yang dimainkannya (Sitorus, 2002: 19).

Selanjutnya yang menjadi penting sebagai catatan yang perlu Penulis garis bawahi dengan tinta tebal ialah, kurangnnya peserta yang memasukkan unsur budaya lokalitasnya dalam pentas monolog, sehingga tidak tampak ciri kedaerahan yang akan pentas. Hal ini seharunya menjadi pertimbangan bagi seluruh tim, bahwa budaya lokal tersebut tidak hanya pada dialek, karena dialek tersebut masih bisa dicari celahnya mungkin karena sang aktor memang belum faseh berbicara bahasa Indonesia dengan nada dan S.P.O.K seperti biasanya. Oleh sebab itu ciri budaya lokal hendaklah tergarap dengan baik dan indentifikasi kedaerahan bisa terbaca, tapi dalam hal ini tidak bisa dirasakan secara maksimal. Ada banyak media pembantu dalam pementasan teater yang bisa memasukkan budaya lokalitas ini, lagi-lagi tergantung dari tim untuk terus bereksplorasi dan melatih segala kebutuhannya untuk pentas.

Tentu saja penggarapan harmonisasi budaya lokalitas perlu diolah dan dieksplorasi lagi, karena poin ini juga masuk dalam penilaian para juri. Sebab dari seluruh pementasan yang berjumlah lima belas group, Penulis hanya menyimpan tiga penyaji yang memasukkan budaya lokalitasnya, itupun kurang maksimal. Bahkan yang lebih ngeri lagi, beberapa peserta malah sibuk untuk ngontemporer, dan bermain-main dengan simbol yang justru malah menjebak pada kebingungan itu sendiri. Sebab yang terlihat akhirnya adalah demonstrasi visual, bukan lagi demonstrasi akting yang melibatkan psikologi, 
fisiologi dan sosiologi tokoh. Karena hampir semua naskah monolog yang dipentaskan, sesungguhnya menampilkan tiga kebutuhan teater tersebut seperti Psikologi, Fisiologi dan Sosiologi untuk lebih mudah kita menyebutnya 3D (tiga dimensi tokoh). Tapi 3D ini belum tergarap dalam wujud pengadeganan dan harmonisasi budaya lokalitas.

Seluruh keterlibatan dari pementasan ini tentu saja tidak lepas dari jendral lapangannya yang menjadi penentu bagaimana karya tersebut akan ditampilkan ke khalayak umum yaitu, sutradara. Jika sutradara salah melakukan interpretasi naskah maka akan salahlah keseluruhan pementasan tersebut. Tapi bersyukurnya adalah bahwa di dalam kesenian salah tersebut sangat relatif sifatnya, bahkan kata salah bisa dicarikan tempat dan kodratnya, sebab seni bukanlah ilmu pasti untuk mengukur segala sesuatu itu benar dan salah. Tetapi karena monolog stigma lima ini bentuknya lomba, maka juri punya pandangan tersendiri dalam menilai kreasi generasi muda. Pertama di beberapa pementasan, yang tampak bahwa sutradara belum maksimal kerjanya dalam menggarap para aktor. Hal ini bisa ditandai dari pengeditan naskah, tata teknis panggung yang terkadang tidak pada tempatnya dan persoalan titik aktor dan emosi aktor yang belum terolah. Siapa yang bertanggungjawab dalam semua ini?

Sudah pasti sutradara, sebab sutradaralah yang mewakili penonton pertama dalam setiap pementasan. Hukum alam di teater memang sedikit tidak adil pada sutradara, tapi memang begitulah kenyataannya, misal: "Jika pementasan itu berhasil dan bagus, maka yang dapat pujian adalah aktornya, akan tetapi jika pementasan itu jelek dan gagal, maka yang dapat hujatan dan hinaan adalah sutradaranya". Tapi tidak masalah, karena semua butuh proses.Seorang sutradara adalah laksana pecinta bertumbuh dari dalam bakat. Penemuan dan kesenangan dalam pekerjaannya, juga bertumbuh dari bakat. Mengelola sebuah produksi, berarti menghimpun atau menyatukan semua orang, benda-benda, untuk bersama-sama membentuk suatu pementasan. Dan melewati reka menciptakan suatu suasana tertentu. Membangkitkan daya tertentu. (Jouvet 18911951; 176-177).

Catatan yang telah disampaikan di atas, segalanya sangat bergantung pada tim sebagai kerja kolektif, dan kerja sutradara yang merajut adegan maupun mengemasnya dalam bentuk yang diinginkan, secara tidak langsung, panca indra sang sutradara diharapkan bisa mewakili penonton untuk mengukur aktor yang akan dipertontonkan di hadapan khalayak. Karena sutradara yang akan menentukan dan menafsirkan dan menata segala yang ada di atas panggung dengan tim kerjanya. Oleh sebab itu evaluasi ini diharapkan bisa menjadi perhatian tim secara bersama terutama sutradara yang menjadi jendral dalam mengambil segala kebijakan dan keputusan. Harmonisasi budaya lokalitas juga sebagai pengingat kepada kita semua, jangan sampai, "semut diseberang pulau tampak, tapi gajah di pelupuk mata tak tampak". Penulis harap jangan berhenti untuk bereksplorasi kepada seluruh tim pementasan monolog stigma lima Malang. 


\section{KESIMPULAN}

Berdasarkan dari pemaparan singkat yang telah disampaikan di atas maka bisa ditarik kesimpulan bahwa konsep stigma lima UM kali ini adalah bagaimana monolog bisa menjadi tuntunan buat penonton tanpa menghilangkan lokalitas yang ada pada wilayah para penyaji. Para penyaji juga perlu menggarap kembali segala kebutuhan teknisnya, bahkan menyiasati segala kendalakendala yang ada. Karena di atas panggung hanya ada satu orang aktor yang pentas, sudah semestinya kebutuhan teknis perlu mendukung sang aktor agar tidak tenggelam dan hilang dalam permainan. Monolog sebagai ruang aktor untuk bercerita sendiri juga perlu di simpan di dalam hati, sebab setelah dipahami, harapannya tidak adalagi yang mis, dan tidak bisa membedakan monolog dengan dialog dan dengan pementasan lakon.

Monolog Nasional stigma lima UM ini juga sudah mempertegas terkait tema, dan secara keseluruhan para penyaji sudah menaatinya, lagi-lagi persoalannya adalah wilayah tafsir dan interpretasi dari masingmasing tim. Sebab di beberapa grup masih bisa dirasakan kurang pengolahan. Tema yang dibuat panitia kali ini secara tidak langsung mengembalikan seni kepada masyarakat, sebab di dalam kesenian ada yang disebut seni untuk seni dan seni untuk rakyat. Seni untuk seni adalah senjata para kapitalis untuk menjauhakan seniman dengan rakyatnya, sementara seni untuk rakyat sudah jelas yang memuat tiga dharma yaitu, seni itu adalah senjata untuk memperhalus budi pekerti karena ia memuat tatanan, tuntunan dan tontonan. Penulis harap semua peserta yang sudah berlomba tetap berlapang dada baik yang kalah maupun yang menang, karena pada akhirnya proseslah yang menentukan. Yang terpenting sebagai insan seni ialah kembali memikirkan dramaturgi sandiwaranya Indonesia tersebut dengan konsep Tri Dharma Teater Nusantara yaitu Tatanan, Tuntunan dan Tontonan. Juga mengemas $5 \mathrm{~W} 1 \mathrm{H}$ yaitu; Wicara, Wirama, Wiraga, Wirupa, Wirasa dan Harmony. Semoga jayalah selalu teater Indonesia, salam budaya.

\section{DAFTAR PUSTAKA}

Alterman, Glenn, 2005.Creating your own monologue, Published by Allworth Press, 10 East 23rd Street, New York, NY 10010

Abdullah, T Imron, 2000. (Editor Nur Sahid), Interkulturalisme dalam Teater, Yayasan Untuk Indonesa; Yogyakarta.

Harrop, John. Akting Theatre concepts series. London: This edition published in the Taylor \& Francis e-Library, 2005.

\& Epstein, Sabin R. Acting With Style (1982). Diterjemahkan oleh Yudiaryani. Jurusan Teater, Fakultas Seni Pertunjukan ISI Yogyakarta. 2008.

Kyrbi, Michael. "On Acting and Not-Acting" dalam Philip B. Zarrilli (ed.), Acting (Re) Considered. London \& New York: Routledge 1998. Diindonesiakan oleh Teuku Ferdiansyah Tadjib \& Landung Simatupang.

Prasetya, Hanggar Budi. Meneliti Seni

Pertunjukan. Yogyakarta: BP ISI Yogyakaryata. 2013.

Mitter, Shomit. Sisitem Pelatihan Stanislavsky, Brecht, Grotowski dan Brook. Penerjemah Yudiaryani, M.A 
(1999). Institut Seni Indonesia Yogyakarta.

Roznowzki, Rob. 2013. Inner Monologue In Acting, By Palgrave Macmillan ${ }^{\circledR}$ In The United States- A Division Of St. Martin's Press LLC, 175 Fifth Avenue, New York, NY 10010.

Riantiarno, Nano, Bakdi, Soemanto. Sphinx Triple X, Antologi Monolog Anti Budaya Korupsi, Jomboran, Sidoarum.

Shengold, Nina. 1987. The Actor's Book Of Contemporary Stage Monologues, A Smith And Krausinc Book.Penguin Books, 40 West 23RD Street. New York, New York 10010. U.S.A.

Sitorus, Eka D. The Art Of Acting, Seni Peran Untuk Teater, Film dan TV. Jakarta: PT. Gramedia Pustaka. 2002.

Toby Cole \& Helen Krich Chinoy,1963 Director On Directing. Terjemahan Dami N. Toda.The Bobbs-Merrill Company, Inc, New York.. P.P. 1226-233. 